\title{
Nutritional Treatment of Anaemia as Compare to Marketed Available Drug (Ferrous Sulfate) in Animal Model
}

Kulsoom Baqa ${ }^{1}$, Nazish Waris ${ }^{1}$, Rana Kausar ${ }^{2 *}$, Anum Butt ${ }^{1}$, Iqra Saleem ${ }^{3}$, Shazia Shaheen ${ }^{3}$, Sumera Rais Abbasi $^{4}$ and Farhana Farhat $^{5}$

${ }^{1}$ Department of Research, Baqai Institute of Diabetology and Endocrinology, Baqai Medical University, Karachi, Pakistan

${ }^{2}$ Associate Professor, Federal Urdu University of Arts Science and Technology, Pakistan

${ }^{3}$ Pakistan Council of Scientific and Industrial Research, Pakistan

${ }^{4}$ Assistant Professor of Biochemistry, Federal Urdu University of Arts Science and Technology, Pakistan

${ }^{5}$ Lecturer of Biochemistry, Federal Urdu University of Arts Science and Technology, Karachi, Pakistan

\begin{abstract}
Aim: To study the nutritional treatment of anaemia as compare to marketed available drug (Ferrous sulfate) in animal model.

Methodology: Total 24 rats were included in the study, divided into 4 groups. Control group was treated with saline. Anaemia was produced in model and both test groups by pricking on their tail and drawn 2-3 drops of blood daily for one week. After producing anaemia model remained same and test group 1 were treated with the marketed available anti-anaemic drug called Ferrous sulphate of $30 \mathrm{mg} / \mathrm{kg}$ body weight and test group 2 treated with natural anti-anaemic Illicium verum extract of $80 \mathrm{mg} / \mathrm{kg}$ body weight for 6 weeks respectively.

Result: Illicium verum extract increases locomotor activity in T2 rats therefore; rats open field activity was increased. It decreases depression and long-term memory but enhanced short term memory. It also produces anxiolytic effect as compare to ferrous sulfate. Haematological study including RBC, PCV, MCHC and platelets were shown significantly increased in $\mathrm{T} 2$ group of rats while lymphocyte, $\mathrm{MCH}$ and $\mathrm{MCV}$ were decreased.

Conclusion: It was concluded in the study that the Illicium verum extract produce same effect as common medicine ferrous sulfate on rat's model. In developing country, such as Pakistan the rate of anaemia was increased so there is a need of finding natural compounds to cure anaemia. Natural remedies were vital in modern era because natural compound do not produce side effect.
\end{abstract}

Keywords: Anaemia; Ferrous sulfate; Illicium verum

\section{Introduction}

Anaemia is defined as a disease, decrease in blood haemoglobin concentration. In anaemia hypoxia occurs because erythrocytes fail to proper supply of oxygen to body tissues [1]. It is common health issue of low, middle and high-income countries and produce bad impact on social and economic development. The most reliable marker for anaemia is to determine blood haemoglobin concentration [2]. Around the world 1.62 billion people effected from anaemia. High prevalence $47.4 \%$ was observed in preschool-age children and low prevalence $12.7 \%$ in man [3].

Iron deficiency anaemia was nutritional disease that causes erythropoiesis and traditional iron supplement cause gastrointestinal irritation [4]. Many iron compounds were used to treat anaemia, one of which is ferrous sulfate that was commonly prescribed medicine by physicians. Ferrous sulfate has high iron content and better absorption, help to relieve symptoms of iron deficiency anaemia which produces side effect such as diarrhoea, epigastric discomfort and constipation [5]. Oral iron is first line treatment of iron deficiency anaemia, but many subjects were not tolerated, not respond to word treatment [6].

Illicium verum (Chinese star anise) is a member of Magnoliacease family, used as flavour in china 5 spices. It is grown in mountain area particularly in lanson province, cochin, south china and Vietnam. Fruit of Illicium verum is star shaped and in each arm seed pod [7]. The fruit of Illicium verum have bitter taste, tannins and essential oil 9-10\%, ethanol 85-90\%, $\alpha$-pinene, limone, $\beta$-phellandrene, $\alpha$-terpineol, farnesol and safrol. By performing chemical analysis of oil identifies 16 compounds and these oils possess antifungal activities [8]. Illicium verum was recognized as both food and medicine by the ministry of health, people republic of china because of low toxicity to human [9]. Iron supplements contain many side effects that's why using natural compound Illicium verum (ethanolic extract) which was easily available in kitchen of every house of Pakistan, used in different dishes and its effect was examined by haematology and behavioural activity. It was determining the ethanolic extract and aqua extract of Illicium verum was beneficial for the treatment of anaemia without any side effect.

\section{Material and Methods}

\section{Quality of animals}

Locally bred male Albino Wister rats weighing about 180 to $200 \mathrm{gm}$ on arrival purchased from animal house of research institute of Agha Khan University Karachi Pakistan were used throughout the experiment. Animals were brought and studied in the Biochemistry department of Federal Urdu University of Arts, Science and Technology, Karachi, Pakistan. These rats were individually kept in specially designed cage with saw dust cover floor in a quiet room, with free access to cubes of standard rat's food and water at least 3 to 4 days before starting the experiment. So, the rats could adapt themselves to the new environment. Total of 24 rats are used, divided into 4 groups, each group consist of six rats. Group 1 called control given saline. Group 2 called model, group 3 and 4 are used as test 1 and 2 respectively. Model and both test groups

${ }^{*}$ Corresponding author: Dr. Rana Kausar, Associate Professor, Federal Urdu University of Arts Science and Technology, Pakistan, Tel: 0333 3404812; E-mail: ahamza286@gmail.com; ranakausar4@gmail.com

Received February 28, 2018; Accepted March 26, 2018; Published April 04, 2018

Citation: Baqa K, Waris N, Kausar R, Butt A, Saleem I, et al. (2018) Nutritional Treatment of Anaemia as Compare to Marketed Available Drug (Ferrous Sulfate) in Animal Model. J Bioanal Biomed 10: 50-55. doi:10.4172/1948-593X.1000204

Copyright: ( 2018 Baqa K, et al. This is an open-access article distributed under the terms of the Creative Commons Attribution License, which permits unrestricted use, distribution, and reproduction in any medium, provided the original author and source are credited. 
were made anaemic by pricking on their tail and drawn 2-3 drops of blood daily for one week. After making them anaemic model remained untreated till the end of the experiment. While, test 1 group of rats were treated with the marketed available anti-anaemic drug called ferrous sulphate and test 2 treated with anti-anaemic Illicium verum extraction for six weak.

\section{Mean weight of animals before treatment}

$$
\begin{aligned}
& \text { RAT-1 group control }(\mathrm{C})=180 \mathrm{gm} \\
& \text { RAT-2 group model }(\mathrm{M})=195 \mathrm{gm} \\
& \text { RAT-3 group drug treated }(\mathrm{T} 1)=190 \mathrm{gm} \\
& \text { RAT-4 group Illicium verum extraction treated }(\mathrm{T} 2)=190 \mathrm{gm}
\end{aligned}
$$

\section{Preparation of saline}

For the preparation of $0.9 \%$ solution of $\mathrm{NaCl}$, take $4.5 \mathrm{gm} \mathrm{NaCl}$ and dissolved it in $500 \mathrm{ml}$ water and then it was freeze to get chilled saline.

\section{Preparation of drug}

Ferrous Sulfate drug was given to $\mathrm{T} 1$ group of rats as $30 \mathrm{mg} / \mathrm{kg}$ body weight, after dissolving in water for six weeks.

\section{Preparation of plant fruit extract}

Illicium verum was crushed and extract was prepared in ethanol for two weeks [10]. Ethanol was evaporated with the help of hot plate magnetic stirrer and precipitates were dissolved in saline water, which was given to T2 rats as $80 \mathrm{mg} / \mathrm{kg}$ body weight for six weeks [11].

\section{Handling}

The oral administration of drugs to laboratory rats require extensive handling and it is recommended that prior to experimental manipulation, such animals should be handled on a regular basis in non-life-threatening situations like weighing, petting, giving food treats. This makes the animals respond positively to handling and learn to recognize individuals. The animals should be handled gently but firmly avoiding loud noises or sudden movements.

To remove the rats from the cage, it is picked up by the tail close to the base and placed on the flat surface of a bench. Holding tail with the right thumb and forefinger, the scruff of the animal is reached for with your left thumb and forefinger. It positioned them firmly on either side of the animal's head at the level of the mandible. While, the rest fingers and palm of the left hand are used to firmly press the thorax or trunk down against the flat surface of the bench. The tail may be held either firmly against the trunk with the fifth finger of the left hand of left hanging free. When held firmly this way, the rat is restrained and the oesophagus is as straight as possible.

\section{Experimental protocol}

Behavioural activities were monitored during treatment after $2^{\text {nd }}$, $4^{\text {th }}$ and $6^{\text {th }}$ weeks, in light and dark environment. Light and dark activity is specific for anxiety the apparatus used in light and dark experiment consisted of small square area $(26 \times 26 \times 26 \mathrm{~cm})$ with an access $(12$ $\times 12 \mathrm{~cm}$ ) walls of one compartment was transparent and other dark. Experiment was performed under normal day light, the experimental rats, were placed on the dark side of the apparatus than observed that how many time takes to rat move in the light portion within $5 \mathrm{~min}$.

For the next five min the activity was monitored in the open field, and the open field apparatus consists of a square area $(76 \times 76 \mathrm{~cm})$ with walls of $42 \mathrm{~cm}$ high. The floor divided by lines into 25 equal squares. An animal taken out from the specialized cage and placed it in the centre. Square of the open field apparatus, rats move from centre square, crossing with all four paws, corner sitting, grooming. These all activities scored for five min. Ten min in home cage specially designed made up of Perspex $(26 \times 26 \times 26 \mathrm{~cm})$ with saw dust covered floor was used for this purpose. This activity was monitored as the number of cage crossing and 0.4 scales of increasing intensities of grooming and gnawing. Home cage activity of experimental rats was scored alternatively in a balanced design home cage apparatus to avoid order effect. Forced swimming test is a test, commonly used to measure the effectiveness of antidepressant, although significant criticisms of its interpretation have been made. Animals are subjected to two trails during which they are forced to swim in acrylic glass cylinder filled with water, and from which they cannot escape. The first trail lasts for $15 \mathrm{~min}$. Then, after $24 \mathrm{~h}$, a second trial is performed that lasts $5 \mathrm{~min}$. The time that the test animal spends in the second trails without making any movement beyond those required to keep its head above water is measured. This immobility time is decreased by various types of antidepressant and also by electroconvulsive shock. The Morris water maze activity is a behavioural procedure, mostly used with rodents. It is widely used in behavioural neuroscience to spatial learning and memory. The task is also used as a tool to study drug-abuse, brain development. In this task firstly put the rat in water maze apparatus in which platform is hidden first trail is for habituation continues for five min than after one $\mathrm{h}$ second trail is for short term memory and not the time to reach the platform then after one day third trail is for long term memory and note the time to reach the hidden plate form [12]. After monitoring these activities, the animals returned to their cages.

\section{Mean weight of animals before decapitation}

$$
\begin{aligned}
& \text { RAT-1 group control }(\mathrm{C})=184 \mathrm{gm} \\
& \text { RAT-2 group model }(\mathrm{M})=146 \mathrm{gm} \\
& \text { RAT-3 group drug treated }(\mathrm{T} 1)=151 \mathrm{gm} \\
& \text { RAT-4 group Illicium verum extraction treated }(\mathrm{T} 2)=177 \mathrm{gm}
\end{aligned}
$$

\section{Blood collection after decapitation}

Rats were decapitated after performing all activities. The blood was collected from neck wound in the EDTA tubes for haematology.

\section{Hematological test}

All haematological tests are performed at Liaqat National Hospital, Karachi, Pakistan. These tests are quantitatively determined in blood. Test include $\mathrm{Hb} \%, \mathrm{RBC}, \mathrm{PCV}, \mathrm{MCV}, \mathrm{MCH}, \mathrm{MCHC}$, TLC and PLT. For haematological analysis XP100 sysmex analyser was used. The principle of this system used was cytometry.

\section{Statistical analysis}

Results were represented as mean, \pm SD $(n=6)$ significant difference by Tukey HSD and Duncan test $\mathrm{p}<0.05$ level from C, M, T1 and T2 following one-way ANOVA.

\section{Results}

\section{Behavioural}

Figure 1a Forced swimming activity show effects on control, model and test groups of rats. Statically analysed by one-way ANOVA $(\mathrm{df} 6,23)$ $(\mathrm{F}=8.73511)(\mathrm{p}<0.05)$ shows that after 6 weeks of treatment depression was markedly decreased in test 2 group of rats as compare to control, 


\section{Forced swimming test}

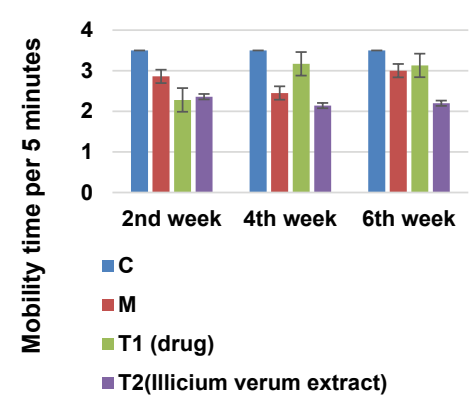

(a)

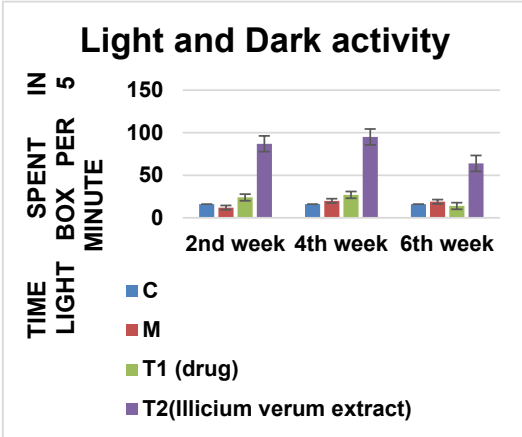

(c)

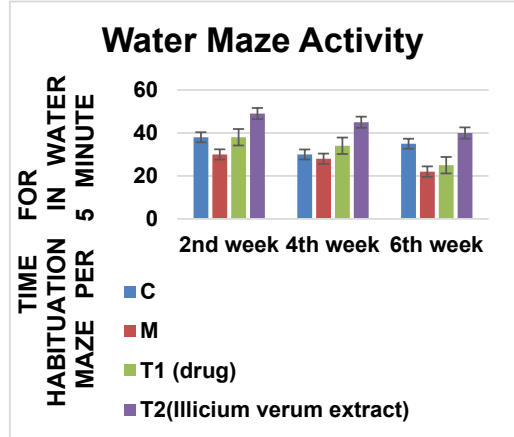

(e)

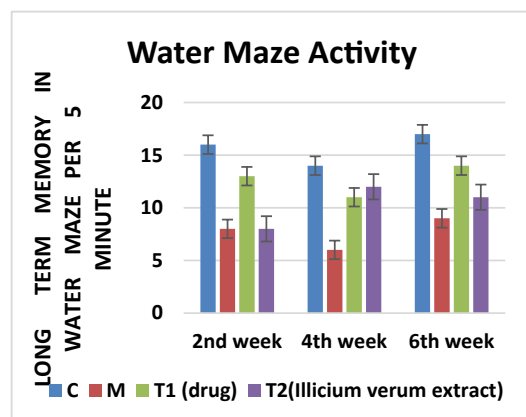

(g)

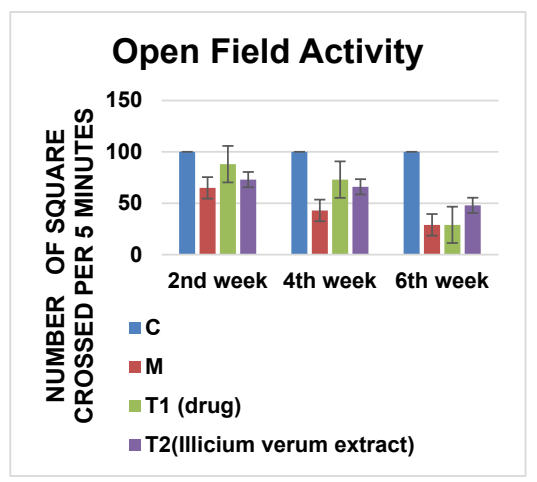

(b)

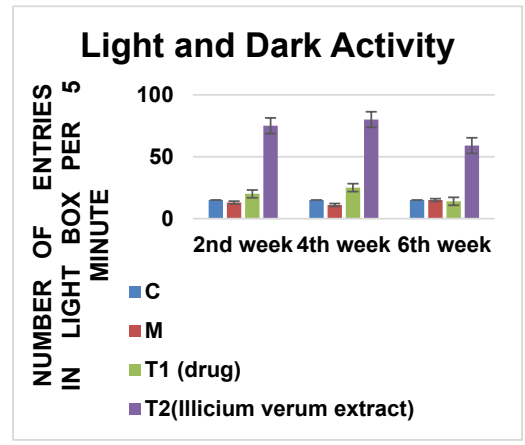

(d)

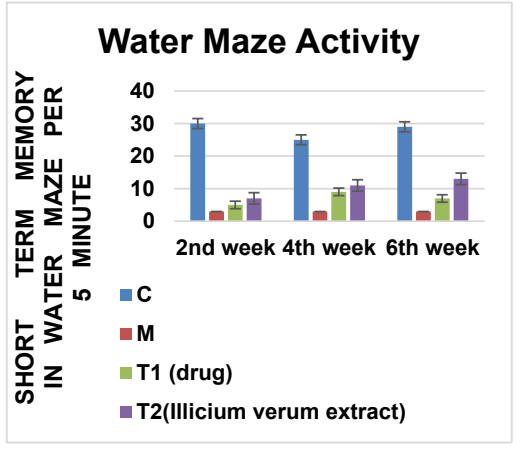

(f)

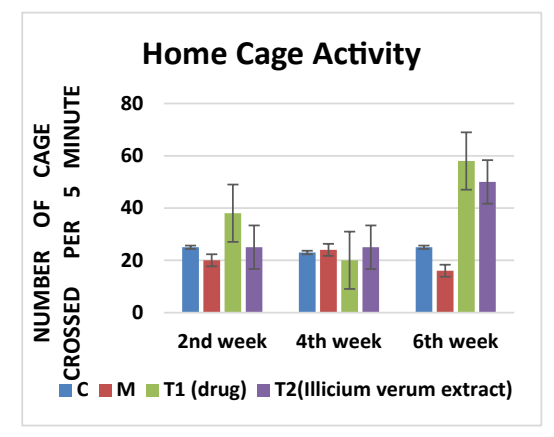

(h)

Figure 1: Comparison of mean values of Behavioural results in Control (C), M, T1 and T2. Behavioural activity. Values are mean \pm SD ( $n=6$ ) significant difference by student t-test $p<0.05$ level from C, M, T1and T2. Behavioural studies including: (a) Forced swimming activity (time of locomotor activity) (b) Open field activity (no. of square crossing) (c) Light and dark activity (time spend in the light box) (d) Light and dark activity (no. of entries in the light box) (e) Water maize test (time for habituation) (f) Water maize test (for short term memory) (g) Water maize test (for long term memory) (h) Home cage activity (no. of cage crossing). 
model and test 1 group of rats. Figure $1 b$ Open field behaviour shows effects on control, model and test groups of rats. Statically analysed by one-way ANOVA $(\mathrm{df} 6,23)(\mathrm{F}=11.31511)\left({ }^{*} \mathrm{p}<0.05\right)$ shows that after 6 weeks of treatment motor activity was markedly increased in test 2 group of rats as compare to model and test 1 group of rats but decreased as compare to control group of rats.

Figure 1c Light and dark activity (time spent in light box per 5 minute) statically analysed by one-way ANOVA $(\mathrm{df6}, 23)(\mathrm{F}=17.4359)$ $\left({ }^{*} \mathrm{p}<0.05\right)$ shows that after treatment anxiety was significantly decreased in test 2 groups of rats as compare to control model and test 1 group of rats. Figure 1d Light and Dark activity (number of entries in light box per $5 \mathrm{~min}$ ) statically analysed by one-way ANOVA $(\mathrm{df6}, 23)(\mathrm{F}=3.99726)(\mathrm{p}<0.05)$ shows that anxiety of test 2 group of rats, decrease significantly as compare to model, but slightly decreases to control, and test 1 groups of rats. Figure 1e Water maze activity (time for habituation in water maze per 5 minute) statically analysed by oneway ANOVA $(\mathrm{df6}, 23)(\mathrm{F}=5.54517)\left({ }^{*} \mathrm{P}<0.05\right)$ shows that recognition memory was markedly increased in test 2 group as compare to control, model and test 1 group of rats.

Figure if Water maze activity (short term memory in water maze per 5 minute) statically analysed by one-way ANOVA (df6,23) $(\mathrm{F}=7.88701)\left({ }^{*} \mathrm{p}<0.05\right)$ shows that recognition memory of test 2 group was decreased as compare to control but increases as compare to model and test 1 group 1 of rats. Figure $1 \mathrm{~g}$ Water maze activity (long term memory in water maze per 5 minute) statically analysed by one-way ANOVA $(\mathrm{df6}, 23)(\mathrm{F}=3.4372)(\mathrm{p}<0.05)$ shows that recognition memory of test 2 group decreases significantly as compare to model group, and decreases as compare to control but memory of test 1 group of rats also significantly increased. Figure $1 \mathrm{~h}$ Home cage activity (number of cage crossed per $5 \mathrm{~min})$ statically analysed by one-way ANOVA $(\mathrm{df6}, 23)$ $(\mathrm{F}=4.44517)\left({ }^{*} \mathrm{P}<0.05\right)$ shows that test 2 group slightly increases as compare to control, model and test 1 group of rats (Table 1 ).

\section{Haematological}

Figure 2a Effects of Illicium verum extract treatment on haemoglobin $(\mathrm{Hb})$ compared between control, model and test groups of rats. Statically analysed by one-way ANOVA $(\mathrm{df6}, 23)(\mathrm{F}=10.832)$ $\left({ }^{*} \mathrm{p}<0.05\right)$ shows that after 6 weeks of treatment haemoglobin was markedly increased in test 2 group of rats as compare to control, model and test 1 group of rats. Figure $2 \mathrm{~b}$ Effects of Illicium verum extract treatment on Red Blood Cell (RBC) shows effects on control, model and test groups of rats. Statically analysed by one-way ANOVA $(\mathrm{df6}, 23)(\mathrm{F}=15.5341)\left({ }^{*} \mathrm{p}<0.05\right)$ shows that after 6 weeks of treatment concentration of RBC was markedly increased in test 2 group of rats as compare to control, model and test 1 group of rats. Figure 2c Packed Cell Volume (PCV) statically analysed by one-way ANOVA (df6,23) $(\mathrm{F}=18.4359)\left({ }^{*} \mathrm{p}<0.05\right)$ shows that after treatment value of PCV was markedly increased in both the tests groups of rats as compare to control and model group.

Figure 2d Statically analysed by one-way ANOVA (df6,23) $(\mathrm{F}=3.99726)(\mathrm{p}<0.05)$ shows that Mean Corpuscular Volume $(\mathrm{MCV})$ significantly decrease as compare to model, but slightly decreases to control in both test groups. Figure 2e Statically analysed by one-way ANOVA $(\mathrm{df6}, 23)(\mathrm{F}=5.54517)\left({ }^{\star} \mathrm{P}<0.05\right)$ shows that Mean Corpuscular Haemoglobin $(\mathrm{MCH})$ markedly increases in test 1 group of rats as compare to control, model and test 2 group of rats. Figure $2 \mathrm{f}$ Statically analysed by one-way ANOVA $(\mathrm{df} 6,23)(\mathrm{F}=7.88701)\left({ }^{\star} \mathrm{p}<0.05\right)$ shows that Mean Corpuscular Haemoglobin Concentration (MCHC) of both test groups was increased as compare to control and model.

Figure $2 \mathrm{~g}$ Statically analysed by one-way ANOVA (df6,23) $(\mathrm{F}=3.3172)\left({ }^{*} \mathrm{p}<0.05\right)$ shows that Platelets Count $(\mathrm{PLT})$ level of both test groups increases significantly as compare to control and model group, but test 2 slightly increases as compare to test 1 group. Figure $2 \mathrm{~h}$ Statically analysed by one-way ANOVA $(\mathrm{df6}, 23) \quad(\mathrm{F}=4.44517)$ $\left({ }^{*} \mathrm{P}<0.05\right)$ shows that Total Leucocyte Count $(\mathrm{TLC})$ level of both test groups also slightly increases as compare to control and model group, are found in normal range.

\section{Discussion}

According to WHO $70-80 \%$ of people specially living in developing world use non-conventional medicine like herbal remedies [13]. To the best of our knowledge, it is the first study from Karachi, Pakistan to report the herbal treatment of anaemia in replacement of ferrous sulfate. In all over the study significant haematological results were observed which increase the herbal importance.

In serum ferritin protein is present which is used as storage of iron. Ferritin is determined in serum. Ferritin level determines the store level of iron in blood when ferritin level decrease it means iron deficiency occur. Serum ferritin replies spontaneously to iron therapy or iron deficiency [14]. In 2012 greater than 6.8 million oral iron prescriptions were not effective in England, 97.6\% subjects were used simple Fe(II) salt. Adverse effect produce on gastrointestinal track is commonly linked with oral iron medication along with nausea, flatulence, abdominal pain, diarrhoea, constipation and black stools [15]. Traditional remedies like use of herbs is common in our history. Different article describes the antioxidant, antimicrobial, antifungal, anti-inflammatory, analgesic, anticonvulsive, insecticidal and sedative

\begin{tabular}{|c|c|c|c|c|c|c|}
\hline $\begin{array}{l}\text { Hematological } \\
\text { Parameters }\end{array}$ & $\begin{array}{l}\text { Mean } \pm \text { S.D of } \\
\text { Control (C) }\end{array}$ & $\begin{array}{c}\text { Mean } \pm \text { S.D of } \\
\text { Model treated (M) }\end{array}$ & $\begin{array}{l}\text { Mean } \pm \text { S.D of } \\
\text { Ferrous sulfate } \\
\text { treated (T1) }\end{array}$ & $\begin{array}{l}\text { Mean } \pm \text { S.D of Illicium } \\
\text { Verum extract treated } \\
\text { (T2) }\end{array}$ & f- value & $\begin{array}{c}\text { P-value } \\
(p<0.05) \text { * }\end{array}$ \\
\hline Hemoglobin ( $\mathrm{Hb} \%)$ & $7.7 \pm 2.14$ & $2.3 \pm 3.14$ & $7.8 \pm 1.18$ & $9.23 \pm 4.87$ & 10.832 & ${ }^{*} p<0.05$ \\
\hline Red blood cell (RBC $\left.10^{3} / \mathrm{ul}\right)$ & $4.1 \pm 3.03$ & $2.9 \pm 2.78$ & $3.1 \pm 1.12$ & $4.46 \pm 2.91$ & 15.534 & ${ }^{*} p<0.05$ \\
\hline Packed Cell Volume (PCV L/L) & $15.9 \pm 5.13$ & $9.8 \pm 4.52$ & $17.9 \pm 6.15$ & $18.75 \pm 6.56$ & 18.4359 & ${ }^{*} p<0.05$ \\
\hline Mean Corpuscular Volume (MCV in fl) & $72 \pm 17.36$ & $25 \pm 10.23$ & $59 \pm 18.11$ & $44 \pm 11.44$ & 3.9972 & $p<0.05$ \\
\hline Mean Corpuscular Hemoglobin ( $\mathrm{MCH}$ in pg) & $21 \pm 9.26$ & $12.5 \pm 3.65$ & $21.52 \pm 8.76$ & $18.86 \pm 6.75$ & 5.5451 & ${ }^{*} \mathrm{P}<0.05$ \\
\hline $\begin{array}{l}\text { Mean Corpuscular Hemoglobin Concentration } \\
\text { (MCHC g/dl) }\end{array}$ & $25 \pm 12.13$ & $24 \pm 9.26$ & $45.5 \pm 15.78$ & $48.23 \pm 13.42$ & 7.8870 & ${ }^{*} p<0.05$ \\
\hline Platelets Count (PLT 10³/ul) & $135 \pm 31.59$ & $188 \pm 345.20$ & $332 \pm 120.45$ & $368 \pm 146.43$ & 3.3172 & ${ }^{*} p<0.05$ \\
\hline Total Leucocyte Count (TLC 103/ul) & $2 \pm 0.04$ & $2.8 \pm 0.68$ & $4.3 \pm 2.12$ & $3.9 \pm 2.02$ & 4.44517 & ${ }^{*} \mathrm{P}<0.05$ \\
\hline
\end{tabular}

Table 1: Mean \pm S.D (Standard Deviation) of Haematological test compared between control (C), Model treated (M) Ferrous sulfate treated (T1), Illicium Verum extract treated $(\mathrm{T} 2)$ 


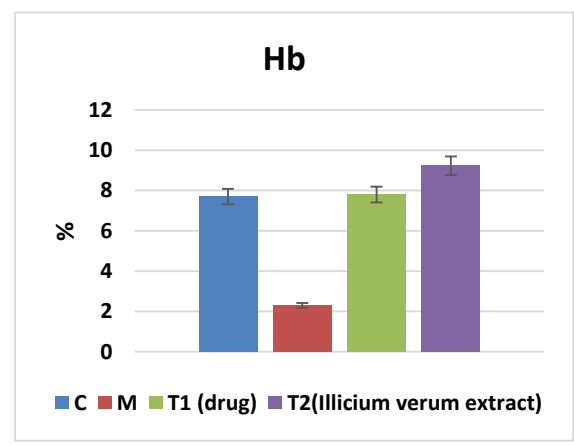

(a)

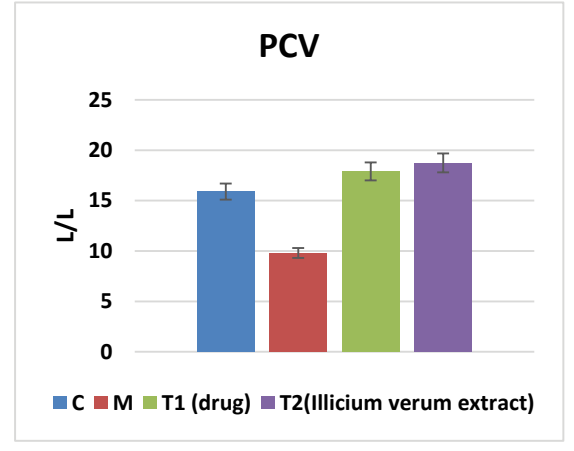

(c)

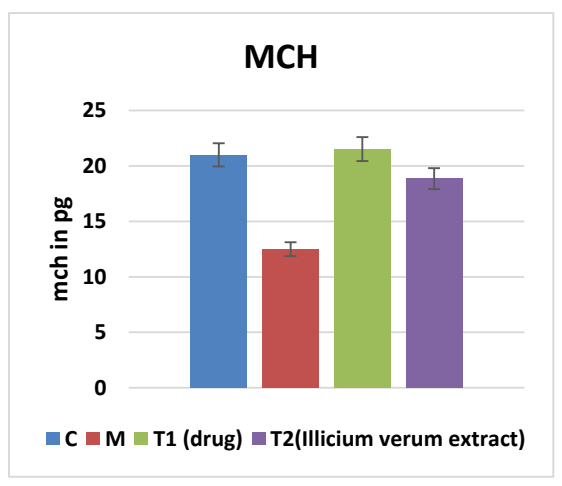

(e)

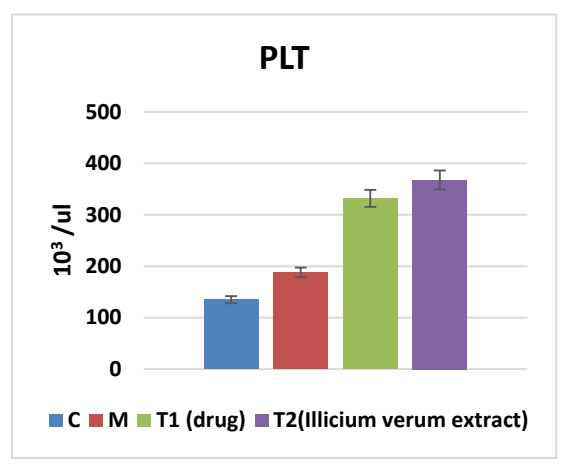

(g)

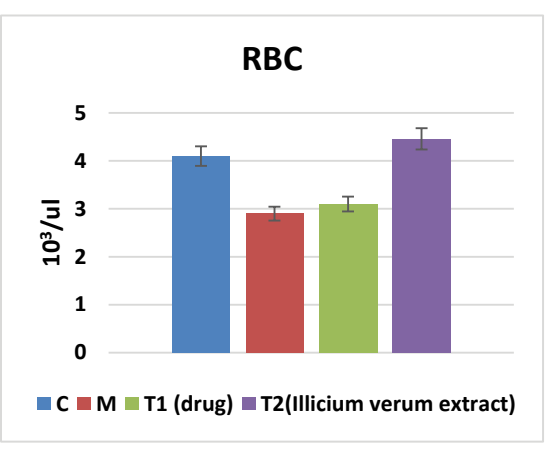

(b)

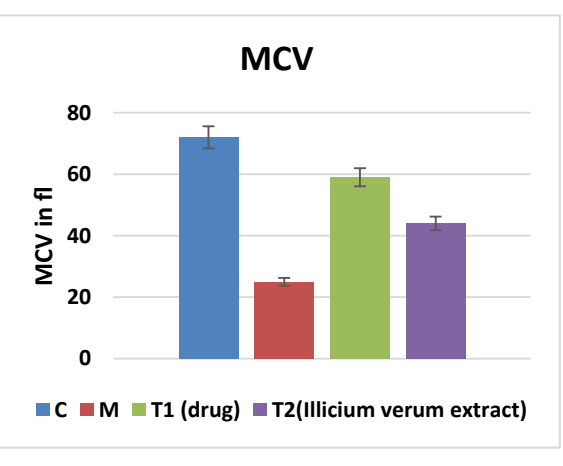

(d)

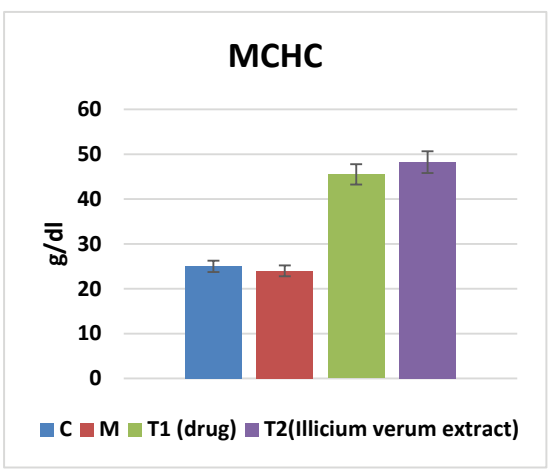

(f)

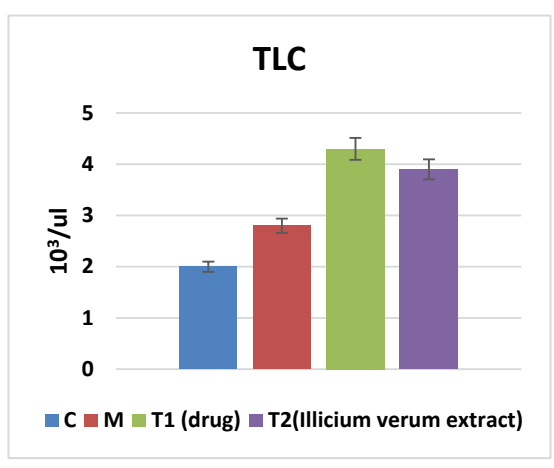

(h)

Figure 2: Comparison of mean values of Haematological results in Control $(C), M, T 1$ and T2 Results were represented as mean, $\pm S D$ ( $n=6$ ) significant difference by Tukey HSD and Duncan test p<0.05 level from C, M, T1 and T2 following one-way ANOVA. (a) Haemoglobin in g/dl (b) RBC in $10^{3} / \mu \mathrm{l}$ (c) PCV in L/L (d) MCV in $\mathrm{fl}(\mathrm{e}) \mathrm{MCH}$ in pg (f) MCHC in g/dl (g) Platelets in $10^{3} / \mu \mathrm{l}(\mathrm{h})$ TLC in $10^{3} / \mu \mathrm{l}$. 
Citation: Baqa K, Waris N, Kausar R, Butt A, Saleem I, et al. (2018) Nutritional Treatment of Anaemia as Compare to Marketed Available Drug (Ferrous Sulfate) in Animal Model. J Bioanal Biomed 10: 50-55. doi:10.4172/1948-593X.1000204

properties of Illicium verum [16]. Previous study reported that Illicium verum was possibly an effective as natural antioxidant source [17].

Study conducted in India describes the roll of some plants that were used to treat anaemia were Eryngium caeruleum (Umbeliferae), Fagonia cretica (Zygophyllaceae), and Aspargus racemosus (Liliaceae) [18]. In this article, illicium verum seed extract was used and found that RBC, haemoglobin and platelet level were significantly increased in rats treated with illicium. Many researches were also conducted on ferrous sulfate for treating anaemia [19]. Previous study reported about fruit extract of illicium verum show sedative and anxiolytic effect on behaviour without affecting motor coordination of central nervous system [8].

Previous study reported that aqueous leaf extract of pumpkin increases the level of erythrocyte, leukocytes and haemoglobin concentration in rat's blood [20]. But there are few studies were available on natural compound to treat anaemia. Iron deficiency anaemia is most common form of anaemia cause by malnutrition and may be caused due to poor iron absorption because of gastric diseases like Crohn's disease. Iron deficiency occurs due to injury with sever blood loss and blood donation [21,22]. Many studies conclude the effect of oral iron supplements produce oxidative stress in gastrointestinal tract and other organ like liver, kidney and heart [23].

\section{Conclusion}

It was concluded in the study that the Illicium verum extract produce same effect as common medicine ferrous sulfate on rat's model. In developing country, such as Pakistan the rate of anaemia was increased so there is a need of finding natural compounds to cure anaemia. Natural remedies were vital in modern era because natural compound do not produce side effect.

\section{Reference}

1. Lee HW, Kim H, Ryuk JA, Kil KJ, Ko BS (2014) Hemopoietic effect of extracts from constituent herbal medicines of Samul-tang on phenylhydrazine-induced hemolytic anemia in rats. Int J Clin Exp Pathol 7: 6179.

2. World Health Organization. The global prevalence of anaemia in 2011.

3. Benoist BD, McLean E, Egll I, Cogswell M (2008) Worldwide prevalence of anaemia 1993-2005: WHO global database on anaemia. World Health Organization 2008.

4. Cui J, Li Y, Yu P, Zhan Q, Wang J, et al. (2018) A novel low molecular weight Enteromorpha polysaccharide-iron (III) complex and its effect on rats with iron deficiency anemia (IDA). Int J Biol Macromol 108: 412-418.

5. Wang FR, Xie ZG, Ye XQ, Deng SG, Hu YQ, et al. (2014) Effectiveness of treatment of iron deficiency anemia in rats with squid ink melanin-Fe. Food Funct 5: 123-128.

6. Hetzel D, Strauss W, Bernard K, Li Z, Urboniene A, et al. (2014) A Phase III randomized, open $\square$ label trial of ferumoxytol compared with iron sucrose for the treatment of iron deficiency anemia in patients with a history of unsatisfactory oral iron therapy. Am J Hematol 89: 646-650.

7. Orwa C, Mutua A, Kindt R, Jamnadass RSA. Agroforest Database-a tree reference and selection guide version 4.0.

8. Sung YY, Kim SH, Kim DS, Lee JE, Kim HK (2017) Illicium verum Extract and Trans-Anethole Attenuate Ovalbumin-Induced Airway Inflammation via Enhancement of Foxp3. Mediators Inflamm 2017: 12.

9. Wei L, Hua R, Li M, Huang Y, Li S (2014) Chemical composition and biological activity of star anise Illicium verum extracts against maize weevil, Sitophilus zeamais adults. $\mathrm{J}$ Insect Sci 14: 80.

10. Kausar R, Waris N (2017) Objective: Treatment by Illicium Verum and Turnip to Cure Cancer without Any Side Effect than Modern Medicine. IOSR-JBB 3: 14-22.

11. Waris N, Kausar R, Waris N, Naz F, Raza A (2017) Effect of extra panadol on blood and behavior of rats. J Bioanal Biomed 9: 206-211.

12. Kausar R, Waris N. Plant isolated compound remove uric acid from blood immediately as compare to anti uric acid drug. Res \& Rev: J Bot Sci 5: 1-5.

13. Karimi M, Mirzaei M, Dehghani A (2004) Prevalence of anemia, iron deficiency and iron deficiency anemia in 6-60 month old children in Yazd's rural area. Int Pediatr 19: 180-184

14. Pollock AS, Lipschitz DA, Cook JD (1978) The kinetics of serum ferritin. Proc Soc Exp Biol Med 157: 481-485.

15. Tolkien Z, Stecher L, Mander AP, Pereira DI, Powell JJ (2015) Ferrous sulfate supplementation causes significant gastrointestinal side-effects in adults: a systematic review and meta-analysis. PloS one 10: e0117383.

16. Kim JY, Kim SS, Oh TH, Baik JS, Song G, et al. (2009) Chemical composition, antioxidant, anti-elastase, and anti-inflammatory activities of Illicium anisatum essential oil. Acta Pharma 59: 289-300.

17. Yang $\mathrm{CH}$, Chang FR, Chang HW, Wang SM, Hsieh MC, et al. (2012) Investigation of the antioxidant activity of llicium verum extracts. J Med Plant Res 6: 314-324.

18. Goswami PK, Ghodgaonkar S, Vishwakarma G, Raut A (2015) Contribution of medicinal plants in treatment of anaemia and as a haematinic. World $\mathrm{J}$ Pharm Pharm Sci 4: 687-702.

19. Shafie EH, Keshavarz SA, Kefayati ME, Taheri F, Sarbakhsh P, et al. (2016) The effects of nanoparticles containing iron on blood and inflammatory markers in comparison to ferrous sulfate in anemic rats. Int J Prev Med 7: 117.

20. Toma I, Victory NC, Kabir Y (2015) The effect of aqueous leaf extract of fluted pumpkin on some hematological parameters and liver enzymes in 2 4-dinitrophenylhydrazine-induced anemic rats. AJBR 9: 95-98.

21. Bark T, Buhr W, Burckhardt S, Burgert M, Canclini C, et al. (2016) Fe (III)pyrazine complex compounds for treatment and prophylaxis of iron-deficiency phenomena and iron-deficiency anaemia. United States patent US 9,439,910.

22. Zhang XG, Wei GX, Wang WN, Ma GD, Tang $P$, et al. (2016) Effects of FeYM1504 on iron deficiency anemia in rats. Food Funct 7: 3184-3192.

23. Nakanishi T, Hasuike Y, Nanami M, Yahiro M, Kuragano T (2015) Novel ironcontaining phosphate binders and anemia treatment in CKD: oral iron intake revisited. Nephrol Dial Transplant 31: 1588-1594. 